\title{
Weights in the Balance: Jasmonic Acid and Salicylic Acid Signaling in Root-Biotroph Interactions
}

\author{
Caroline Gutjahr and Uta Paszkowski \\ Department of Plant Molecular Biology, University of Lausanne, Biophore Building, $\mathrm{CH}-1015$ Lausanne, Switzerland \\ Submitted 9 December 2008. Accepted 13 March 2009.
}

\begin{abstract}
Work on the interaction of aerial plant parts with pathogens has identified the signaling molecules jasmonic acid (JA) and salicylic acid (SA) as important players in induced defense of the plant against invading organisms. Much less is known about the role of JA and SA signaling in root infection. Recent progress has been made in research on plant interactions with biotrophic mutualists and parasites that exclusively associate with roots, namely arbuscular mycorrhizal and rhizobial symbioses on one hand and nematode and parasitic plant interactions on the other hand. Here, we review these recent advances relating JA and SA signaling to specific stages of root colonization and discuss how both signaling molecules contribute to a balance between compatibility and defense in mutualistic as well as parasitic biotroph-root interactions.
\end{abstract}

Biotrophic plant invaders encompass a wide variety of organisms including bacteria, fungi, worms, and parasitic plants. Their relationships with host plants result in different outcomes that range from mutually beneficial to parasitic. Biotrophs either insert feeding structures into living plant cells or induce and inhabit special plant-derived organs to exploit living material (Fuller et al. 2008; Glazebrook 2005; Oldroyd and Downie 2008). Their recognition by the plant triggers complex, multistep signaling cascades leading to accommodation or combat of the colonizer. Phytohormones contribute to modulating such defense and accommodation processes and, among them, jasmonates and salicylic acid (SA) have received considerable attention (Bari and Jones 2009; Beckers and Spoel 2006; Ding and Oldroyd 2009; Glazebrook 2005; Hause et al. 2007). According to genetic evidence retrieved from studies on Arabidopsis thaliana defense against biotrophic leaf pathogens generally involves SA-dependent signaling, whereas inducible defense against leaf-chewing insects and necrotrophic microbes is mediated by jasmonic acid (JA)-dependent signaling (Balbi and Devoto 2008; Beckers and Spoel 2006; Browse 2009; Glazebrook 2005; Loake and Grant 2007). However, exceptions and more complex scenarios exist, depending on environmental or experimental conditions or a combination of biotrophic and necrotrophic lifestyles for various pathogens (Glazebrook 2005; López et al. 2008; Robert-Seilaniantz et al. 2007; Spoel and Dong 2008). Furthermore, SA and JA signaling frequently interact either antagonistically or synergistically, depending on the combination of their respective concentrations (Koornneef et al. 2008; Mur et al. 2006). This means that both SA and JA

Corresponding author: Caroline Gutjahr; Fax: ++41-21-692 4195; E-mail: caroline.gutjahr@unil.ch can impact biotrophic interactions and that the negative crosstalk between JA and SA signaling can be exploited by pathogens to enhance plant susceptibility. A prominent example is provided by the hemibiotrophic bacterium Pseudomonas syringae, which uses the phytotoxin coronatine, a substance similar to jasmonate-isoleucine (JA-Ile) (Katsir et al. 2008) to repress the SA-mediated defense pathway (Brooks et al. 2005; Laurie-Berry et al. 2006).

A number of excellent reviews describe the current understanding of the complex signaling network involved in the plant's defense against biotrophic foliar pathogens (Bari and Jones 2009; Beckers and Spoel 2006; Glazebrook 2005; Lipka et al. 2008; López et al. 2008; Robert-Seilaniantz et al. 2007). In contrast, very little is known about the importance of SAand JA-mediated signaling in root biotrophic interactions. This field is presently emerging through studies on plant interaction with exclusively root-colonizing biotrophs. Among these are beneficial rhizobial and arbuscular mycorrhizal (AM) symbioses on one hand and detrimental infections by nematodes and parasitic plants on the other hand. Interestingly, plant signaling components leading to root colonization are partly shared between these interactions (Mathesius 2003; Paszkowski 2006), which is inviting for comparisons of compatibility and defense. In this review, we describe current knowledge of the role of SA and JA signaling in root-biotroph interactions. When possible, we relate SA and JA signaling to defined stages of the colonization process. Also, when available reports permit, we put observations on SA and JA signaling in root-biotroph interactions in relation to the general model for leaf parasites (Glazebrook 2005) and conclude with a discussion of the differences and similarities between the interaction of mutualistic and parasitic biotrophs with the "hidden plant organ."

\section{MUTUALISTIC ASSOCIATIONS: AM AND LEGUME-RHIZOBIUM SYMBIOSES}

Precontact recognition: JA modulates electrophysiological signals.

Diffusible elicitors released by microbes trigger plant responses before physical cell-to-cell contact occurs (GarciaBrugger et al. 2006; Garcia-Garrido and Ocampo 2002; Kosuta et al. 2003; Olah et al. 2005). Similarly, the colonization of plant roots by AM fungi and rhizobia is preceded by a molecular dialogue to establish recognition. Rhizobia react to host root-derived flavonoids by the production of Nod factors, which, upon perception, induce the plant's nodulation program (Hirsch et al. 2001; Radutoiu et al. 2007). Nod factors and approaching AM fungi induce calcium spiking in root hairs (Kosuta et al. 2008). In rhizobial symbioses, calcium spiking 
acts as a secondary messenger and activates Nod factor-induced gene expression, infection thread (IT) formation, and nodule organogenesis (Oldroyd and Downie 2008). Its role in AM symbioses has not yet been directly addressed.

JA exogenously applied to the growth medium decreases the number of nodules induced by Sinorhizobium meliloti on Medicago truncatula roots in a dose-dependent manner (Sun et al. 2006). This result could be attributed to JA-mediated cell-cycle inhibition (Swiatek et al. 2002) during nodule formation. However, JA seems to even suppress nodule initiation, as nodule primordia were absent and induction of two Nod factor-responsive marker genes (RIPI and ENOD11) was blocked. Assessment of the impact of JA application on calcium spiking revealed that JA decreases the responsiveness of calcium spiking to Nod factor in a dose-dependent manner. Whereas high concentrations $(100 \mu \mathrm{M})$ of JA strongly inhibited calcium spiking, lower concentrations (10 to $50 \mu \mathrm{M})$ modified the calcium signal by lengthening the spike period, thereby decreasing the frequency of spiking (Sun et al. 2006). Modulation of the calcium signature might have an important role in fine tuning the initiation of colonization in an interplay of Nod factor and JA concentrations. Indeed, the number of calcium spikes is critical for triggering the Nod factor signaling pathway (Miwa et al. 2007). Similar calcium oscillations are also important for other strictly regulated systems, such as stomatal opening, for which calcium oscillation in guard cells needs to follow defined parameters for a change in the stomatal state to occur (Allen et al. 2001). It is tempting to speculate that JA participates in adjusting the amount of colonization to a level that the plant can support under a given environmental condition. However, it should be noted that the effect of JA on calcium spiking has been shown exclusively by pharmacological application. Therefore, the relevance of endogenous JA for calcium spiking at the onset of rhizobial colonization remains to be determined by genetic studies. If JA acts on calcium spiking, it could also be expected to influence AM symbioses at this early stage. Identification of one or more targets of JA-mediated inhibition of calcium spiking will immensely increase our understanding of symbiosis regulation.

Roots of soybean and wheat have been reported to secrete JA into the rhizosphere (Creelman and Mullet 1995; Dathe et al. 1994) showing that rhizosphere organisms might be exposed to JA molecules. The direct effect of JA on AM fungi is not known. However, JA and methyl jasmonate (MeJA) exogenously applied to rhizobia induced the expression of Nod genes (Rosas et al. 1998) and the production of Nod factors (Mabood et al. 2006). The effect of JA on Nod-factor production was enhanced when JA was coapplied with flavonoids (Mabood et al. 2006; Rosas et al. 1998), which are known to induce nod-factor production (Hirsch et al. 2001). In the natural ecosystem, rhizobia can thus potentially balance the JA-mediated decrease in nod-factor responsiveness of calcium spiking by a JA-promoted augmentation of nod-factor production. In summary, JA signaling appears to be involved in balancing the interplay between roots and microbes at the initial events of colonization.

\section{Cell-to-cell contact: Inhibition vs. mediation of cell-autonomous compatibility.}

Recognition between plants and their colonizers is a multistep process allowing decisions to be made at each level of colonization. Precontact signaling molecules, like rhizobial Nod factors or AM fungal Myc factors, prime the plant for the symbiotic program. Upon physical contact however, the microbe has to overcome further checkpoints. AM fungi form a hyphopodium from which a penetration hyphae passes through the rhizodermal cell cytoplasm guided by a prepenetration apparatus (PPA) (Genre et al. 2005). The fungus then apoplastically passes the outer cell layers and develops arbuscules in cell files of the inner cortex. Most rhizobia invade through root hairs and migrate within a structure similar to the PPA, the socalled IT (Fournier et al. 2008). The IT grows inward through the root hair, the rhizodermis, and cortex and releases rhizobia into the inner cells of the simultaneously initiated nodule, in which nitrogen fixation occurs (Oldroyd and Downie 2008). PPA and IT formation might provide a first checkpoint at which the plant can manipulate the success of the colonizer. The intercellular colonization of cells by arbuscules or of nodules by rhizobia is another process that must be under tight plant control (Parniske 2000, 2008).

SA signaling in cell-to-cell contact. Indeed, legumes strictly control the number of successful rhizobial infection events and can reject the bacteria at any stage of the interaction through a rapid defense reaction (Baron and Zambryski 1995). For example, once a certain number of nodules is reached in wild-type Medicago sativa colonized by Sinorhizobium meliloti, hypersensitive response (HR)-like abortions of IT accompanied by cell necrosis and accumulation of phenolic compounds occur at the sites of IT formation (Vasse et al. 1993). Moreover, rhizobia with defects in surface polysaccharides that serve for recognition upon attachment elicited defense reactions similar to HR in alfalfa and pea (Niehaus et al. 1993; Perotto et al. 1994). Additionally, it has been reported that plant mutants that do not allow colonization by AM fungi show various responses similar to HR that likely contribute to the rejection of the colonizer (Genre and Bonfante 2002; Gianinazzi-Pearson et al. 1996; Gollotte et al. 1993).

It could be hypothesized that these HR-like symptoms might be linked to SA-mediated defense signaling if SA function in leaves was conserved in roots. In support of such a hypothesis, it was shown by exogenous application to rice roots that SA interferes with susceptibility to AM fungi by slowing down the onset of intraradical colonization without influencing the number of extraradical hyphopodia (Blilou et al. 2000). More importantly, at early stages of the AM interaction, SA levels transiently increase in roots of wild-type rice and pea, probably in response to hyphopodia formation on the root surface (Blilou et al. 1999, 2000). This SA increase is mirrored by a transient elevation in defense-gene expression in Medicago truncatula roots at early stages of AM colonization (Liu et al. 2003). In the pea mutant sym30, which is resistant to colonization by AM fungi and rhizobia (Duc et al. 1989), the initial SA increase persists (Blilou et al. 1999). The same was found when wildtype pea roots or alfalfa roots were inoculated with an incompatible Rhizobium strain or a mutant strain defective in Nodfactor production, which abolishes symbiont recognition by the plant (Blilou et al. 1999; Martinez-Abarca et al. 1998). This suggests that, after physical contact, the symbiont is confronted with a defense response that involves SA and subsequently needs to be switched off to allow colonization. In the above examples, defense suppression does not occur if the symbiosis is defective at an early step of the interaction-be it on the side of the plant or the microbe. To investigate whether the correlation between increased SA levels and rejection of symbiotic colonization is a general phenomenon, it would be interesting to determine if elevated SA levels are also persistent in other nonmycorrhizal or nonnodulating mutants.

Exogenous addition of SA inhibited formation of indeterminate nodules in vetch but not of determinate nodules in Lotus japonicus (van Spronsen et al. 2003) and also inhibited rhizobial growth (Stacey et al. 2006). To test the effect of endogenous SA levels on nodulation, Stacey and associates (2006) expressed NahG, a bacterial salicylate hydroxylase that degrades SA to catechol (Gaffney et al. 1993) and therefore leads to de- 
creased SA levels, in Lotus japonicus plants. Roots of these transgenic plants displayed an increase in formation of determinate nodules, which was inversely correlated with SA levels in individual transgenic lines. The increase in nodule number was caused by enhanced IT formation, suggesting that endogenous SA inhibits the formation of this early infection structure.

Also, the establishment of an AM symbiosis was affected by endogenous SA levels at early stages of colonization. In Nicotiana tabacum plants expressing $\mathrm{NahG}$, the level of SA accumulation was reduced, which led to an elevation of AM colonization at early timepoints postinoculation, including higher numbers of infection units and arbuscules (Herrera Medina et al. 2003). On the contrary, in tobacco plants that constitutively produce elevated levels of SA, lower colonization levels were observed at early timepoints. The effects of modified SA levels on AM colonization were no longer detectable at later timepoints postinoculation (Herrera Medina et al. 2003), indicating that SA-mediated inhibition of AM colonization mainly leads to a colonization delay. This might be interpreted as a repression of early infection events that is, at later stages, compensated by extensive spread of fungal intraradical hyphae. In summary, SA acts at the first cell-to-cell contact between the symbionts to reduce colonization. During rhizobial colonization, SA suppresses IT formation (Stacey et al. 2006). For AM colonization the exact stage of inhibition has not been described, but PPA formation is a good candidate target (Fig. 1A). In this context, it is intriguing that, in Medicago truncatula hairy roots, a class 10 pathogenesis-related protein (PR-10) was upregulated in root cells close to the hyphopodium and subsequently repressed during formation and fungal passage of the PPA (Siciliano et al. 2007). It can be experimentally addressed whether the spatio-temporal expression pattern of this PR-10encoding gene marks SA activity. It would further be interesting to combine pharmacological SA application with live imaging (Genre et al. 2005; Fournier et al. 2008) to document the effect of SA on early infection structures.

JA signaling in cell-to-cell contact. How might initial SAmediated defense signaling be switched off to avoid abortion of the symbiotic colonization event at the rhizodermis? Mutually inhibitory crosstalk between JA and SA signaling is a common and generally accepted phenomenon in plant shoots (Beckers and Spoel 2006; Glazebrook 2005; Glazebrook et al. 2003; Lorenzo and Solano 2005). Although, in the absence of evidence, several hypotheses can be brought forward, it is a particularly appealing possibility that JA signaling might counterbalance SA signaling at early stages of root symbioses-possibly in response to perception of microbial effector molecules by the plant. Genes encoding JA-biosynthetic enzymes are upregulated in Lotus japonicus at early colonization steps by Mesorhizobium loti and then repressed upon nodule formation (Kouchi et al. 2004), while SA-responsive PR-encoding genes are repressed in Medicago truncatula (Godiard et al. 2007; Mitra and Long 2004). This suggests that JA might be acting early in rhizobial colonization, during a step downstream of calcium spiking and upstream of nodule formation. At present however, it still remains an open question if JA signaling is actually occurring and counteracting or, rather, supporting SA signaling (Koornneef et al. 2008; Mur et al. 2006) in the abortion of early infection structures. JA-deficient legume mutants are necessary to address these issues.

Colonization by AM fungi leads to increased JA levels in roots of barley and barrel medic (Hause et al. 2002; Isayenkov et al. 2005; Stumpe et al. 2005). The increase is most pronounced at later stages of the symbiosis and has been related to arbuscule formation, which will be discussed below (Hause et al. 2002). However, a weak JA elevation measured in complete root systems at early timepoints postinoculation (Hause et al. 2002) suggests that JA accumulation might also occur in response to early infection structures. It could be interpreted as dilution of considerably high JA concentrations in a small number of cells that are in contact with early structures such as hyphopodia or penetrating hyphae. Since JA levels were correlated to overall AM colonization by Hause and associates (2002), no conclusions can be drawn with respect to the presence and quantity of individual fungal structures. Plants transformed with reporter genes fused to JA-responsive promoters (Stenzel et al. 2008) are useful tools to visualize JA distribution in roots at the cellular level during all stages of colonization by AM fungi and rhizobia. They could be used to get a first glimpse on a possible interaction of SA and JA signaling at early stages of colonization.

A cell-specific role for JA signaling has been shown in cortex cells containing arbuscules. It has been reported that JAinduced genes and enzymes are expressed specifically in these

A
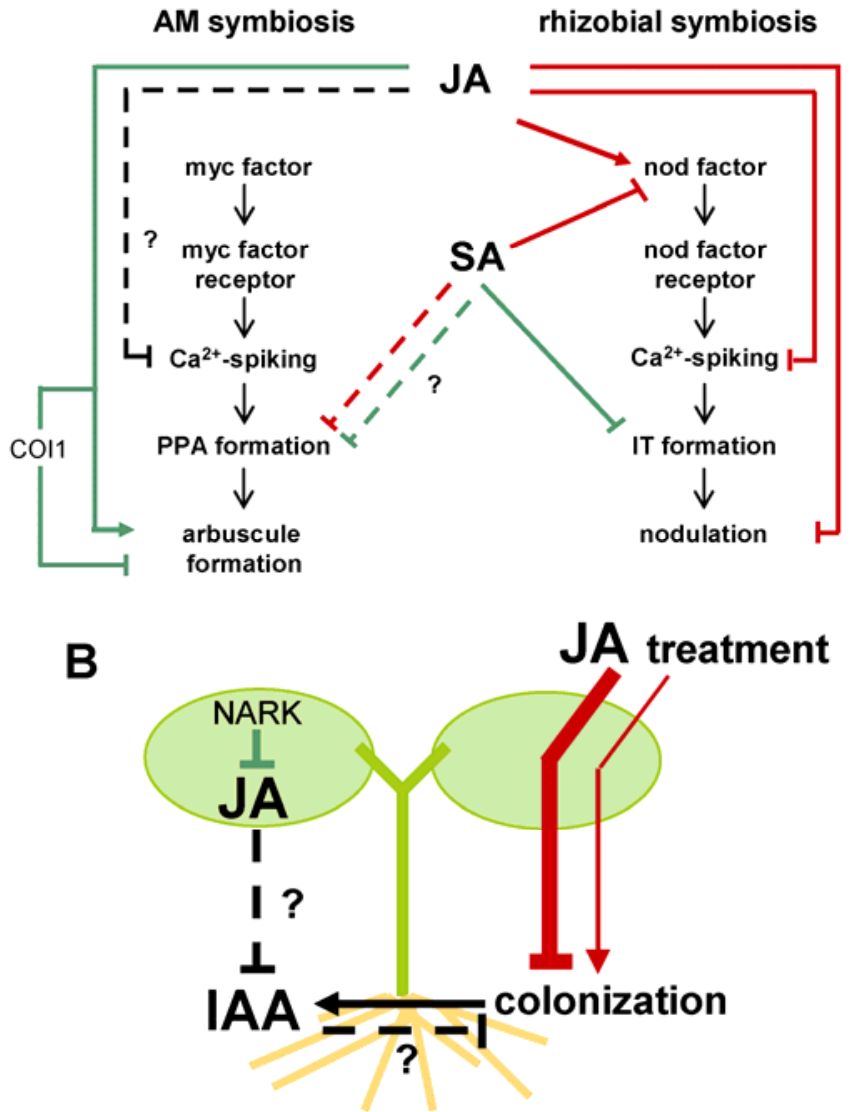

Fig. 1. A, Schematic representation of the influence of jasmonic acid (JA) and salicylic acid (SA) signaling on various steps of root colonization by mutualistic arbuscular mycorrhizal (AM) fungi and rhizobia. B, Modulation of mutualist colonization by systemic JA signaling. Data from rhizobial and AM symbioses are united in one model. Application of JA to shoots at high concentrations or high frequency (bold red arrow) inhibits and at low concentrations and low frequency (fine red arrow) increases root colonization. AM colonization induces indole-acetic acid (IAA) levels in roots, which possibly inhibits further colonization. GmNARK suppresses JA biosynthesis in shoots, thereby suppressing colonization. In the Gmnark mutant, JA levels in shoots are increased, which enhances root colonization. This might occur through suppression of IAA levels in the root. Green indicates evidence obtained via genetic approaches, and red displays evidence obtained by pharmacological application of the hormone. Black indicates hypotheses or data that were obtained in the wild type without pharmacological hormone application. Dotted lines decorated with question marks represent hypothetical scenarios for which no experimental evidence is yet available. 
cells, indicating cell-specific JA accumulation. Arbusculated cells of Medicago truncatula express the enzyme allene oxide cyclase (AOC) (Isayenkov et al. 2005), which catalyzes a key step in JA biosynthesis. In barley transcripts and proteins of the JA-biosynthetic enzyme, allene oxide synthase (AOS) and the jasmonate-inducible protein JIP23 accumulate in arbusculated cells (Hause et al. 2002). The importance of JA in arbuscule formation was demonstrated by RNAi-mediated knockdown of $A O C$ in roots of Medicago truncatula (Isayenkov et al. 2005). A strong decrease in root JA levels due to silencing of $A O C$ was correlated with a significant delay of mycorrhizal colonization and especially a reduction in arbuscule numbers. $A O C$ was downregulated in roots of composite RNAi lines but not in shoots, in which JA levels still increased in response to AM (Isayenkov et al. 2005). Although the authors were therefore not able to exclude effects of a systemic hormone imbalance, this finding represents an important step forward in assigning a role to JA in arbuscule formation. Recently, these results were confirmed in the tomato JA-deficient mutant spr2 (suppressor of prosystemin-mediated responses 2), which is defective in a fatty acid desaturase required for JA biosynthesis (Li et al. 2003). In this mutant, arbuscule numbers were reduced as well and could be restored to wild-type levels by exogenous application of JA. In turn, an overexpressor of prosystemin displaying elevated JA levels showed enhanced colonization (Tejeda-Sartorius et al. 2008). AM colonization thus appears to be related to endogenous JA levels. In contrast to these results, AM colonization was accelerated and arbuscule abundance and functionality was increased in the tomato mutant jail (Herrera Medina et al. 2008), which is defective in COI1, a component of the JA-Ile-receptor complex (Katsir et al. 2008; Li et al. 2001). Nicotiana attenuata plants post-transcriptionally silenced for COI1 also displayed elevated AM colonization (Riedel et al. 2008). These contrasting results between mutants perturbed in JA accumulation and JA-Ile perception can be explained if COI1-mediated JA signaling limits mycorrhizal colonization while JA-mediated support of colonization and arbuscule formation is independent of COI1 function. However, this hypothesis needs further confirmation through the simultaneous examination of mutants defective in JA biosynthetic enzymes and COI1 in the same genetic background and the same experimental setting.

How could JA support AM colonization and arbuscule formation? Simultaneous localization of the JA-responsive JIP23 protein in barley phloem companion cells and in arbusculated cells led Hause and associates (2002) to speculate that JA could be involved in increasing the sink strength of arbusculated cells for carbohydrates that the plant supplies to the fungus. Differential expression of genes encoding enzymes involved in carbon partitioning in tomato mutants with modified endogenous JA levels point in this direction (Tejeda-Sartorius et al. 2008). JA signaling is further known to be involved in defenses against parasites that breach the cell wall and has been designated, therefore, the "cell-ingress pro-hormone" (Farmer 2007). Thus, in an alternative scenario, JA could be necessary for accommodation of the arbuscule in the cell (Hause et al. 2007) independent of the nourishment of the fungus. Arbuscule formation causes invagination and a several-fold extension of the plant cell plasma membrane relative to the original surface area (Hause and Fester 2005). The apoplastic space between the plant and the fungal membrane remains continuous with the cell wall of neighboring cells and contains loosely assembled cell-wall material (Balestrini and Bonfante 2005). Extension of cell wall and membrane in response to the dramatic force applied to the cortex cell by a growing arbuscule must require a fine-tuned dialogue between the symbionts to avoid an abortive defense reaction. Thus, in response to developing arbuscules, JA signaling might create a supportive environment for cell-wall extension by promoting modifications in cell-wall composition. An example for a possible link between cell-wall integrity and JA signaling is given by the Arabidopsis mutants cev1, deficient in the cellulose synthase $C e S A 3$ and therefore root cellulose content, and cobra5, deficient in a glycosylphosphatidylinositol (GPI)-anchored protein that modulates cellulose deposition; both mutants lack crucial cell-wall components and show elevated JA levels and increased JA-related gene expression (Ellis et al. 2002; Ko et al. 2006). Alternatively or additionally, JA signaling might directly activate cell expansion, as in developing potato tubers (Koda 1997; Takahashi et al. 1994), for example through activation of cell wall-cleaving enzymes. Also cytoskeletal rearrangements, which have been observed in arbusculated cells (Genre and Bonfante 1998), might be induced by JA (Koda 1997; Matsuki et al. 1992).

In summary, SA signaling controls mutualist colonization by inducing cell-autonomous defense reactions during early encounters between the symbionts. JA seems to play a role at multiple steps of the colonization. It appears to promote accommodation of AM fungi at later stages of colonization and to suppress AM colonization via the COI1-mediated signaling pathway (Fig. 1A).

\section{Systemic influence on the quantity of colonization: JA-balanced susceptibility.}

Biotrophic symbionts consume considerable amounts of carbohydrates. For example up to $20 \%$ of the plant's photoassimilate are invested in the AM symbiosis (Kucey and Paul 1982; Wang et al. 1989; Wright et al. 1998). To avoid excessive carbon losses, plants need to control the amount of colonization. This autoregulation is most evident in split-root systems in which rhizobial or AM colonization of one half of the split root suppresses subsequent colonization of the other half. The two symbioses also mutually suppress each other (Catford et al. 2003), indicating that related mechanisms control the amount of colonization by both microbes. It is, therefore, not surprising that some hypernodulating mutants also display elevated AM colonization (Meixner et al. 2005; Shrihari et al. 2000; Solaiman et al. 2000).

Systemic effects of endogenous JA. LjHARI/MtSUNN/ $G m N A R K$ is a CLAVATA1-like leucine-rich repeat (LRR) receptor kinase required for autoregulation of nodulation. Through grafting experiments, it was shown to act systemically from the shoot (Krusell et al. 2002; Nishimura et al. 2002; Schnabel et al. 2005; Searle et al. 2003). A search for downstream signals of GmNARK (Glycine max nodule autoregulation receptor kinase) via transcriptional profiling revealed that a group of jasmonate-responsive genes, including those encoding JA biosynthetic enzymes and an orthologue of the transcription factor $M Y C 2$, which is involved in JA signaling (Lorenzo et al. 2004), was constitutively upregulated in shoots of Gmnark mutants (Kinkema and Gresshoff 2008; Seo et al. 2007). The SA-inducible gene encoding PR protein PR1a, in turn, was suppressed (Seo et al. 2007). Furthermore, while, in wild-type shoots, JA-responsive genes were downregulated upon nodulation, expression levels remained high in the GmNARK mutant shoots irrespective of rhizobial colonization (Kinkema and Gresshoff 2008). The differences in gene expression were correlated with JA levels that were twice as high in Gmnark mutant leaves than in wild-type leaves (Seo et al. 2007). Functional evidence for the relevance of systemic JA signaling in enhancing nodule formation was obtained by application of the JA-biosynthesis inhibitor n-propyl gallate to shoots (Kinkema and Gresshoff 2008). The treatment significantly reduced nodule numbers in Gmnark mutant roots without affecting wild-type nodulation. GmNARK thus dampens JA signaling constitu- 
tively and controls nodulation via further suppression of JA biosynthesis and signaling. Conversely, enhanced levels of JA in the shoot systemically promote root nodulation.

How could elevated JA levels in the Gmnark mutant contribute to increasing nodulation? Meixner and associates (2005) showed, in split-root systems using soybean wild type, that mycorrhizal colonization of one part of the split root suppressed colonization of the second part. In the Gmnark mutant, no such suppression was observed. Measurement of phytohormones in mycorrhizal and nonmycorrhizal parts of split roots revealed an increase of indole-acetic acid (IAA) levels in the colonized half. The increase was twofold higher in wild type than in nark mutant roots, suggesting that high auxin might participate in the systemic suppression of mycorrhizal colonization. The fact that application of auxin transport inhibitors increases nodulation and mycorrhizal colonization (Wasson et al. 2006; Xie et al. 1998) supports this idea. On the basis that equal mechanisms of NARK-dependent autoregulation control rhizobial and mycorrhizal colonization, it could be suggested that enhanced JA levels and signaling in the shoots of nark mutants might either inhibit auxin transport to the colonized parts of the root or suppress auxin biosynthesis, thereby limiting the amount of auxin that can be transported. It fits the picture that, in Arabidopsis, the JA-responsive transcription factor MYC2, the orthologue of a gene upregulated in Gmnark shoots (Kinkema and Gresshoff 2008), inhibits the synthesis of the IAA precursor tryptophan and induces the production of flavonoids that act as IAA-transport inhibitors (Dombrecht et al. 2007). Systemic JA signaling might also affect localized SA signaling responsible for abortion of infection events (discussed above). Elevated JA levels in the shoot might further lead to enhanced carbohydrate partitioning to the root (Babst et al. 2005; Henkes et al. 2008), such that a higher number of rhizobia can be nourished. Suppression of endogenous JA biosynthesis in the shoot thus could contribute to keeping colonization levels within boundaries. On the other hand, enhanced JA levels have been implicated in signaling nutrient deficiency (Armengaud et al. 2004; Schmelz et al. 2003; Tang et al. 2001) and systemic JA signaling might increase root colonization (or release suppression) in conditions in which the plant needs enhanced nutrient supplies from the symbiont.

Systemic effects of exogenously applied JA. Systemic effects on symbiotic root associations of exogenous SA application to shoots have not been observed (Ludwig-Müller et al. 2002; Nakagawa and Kawaguchi 2006). In turn, contradictory results were obtained when JA was exogenously applied to plants. In contrast to the findings of Kinkema and Gresshoff (2008) based on elevated endogenous JA levels, exogenous application of JA to shoots inhibited nodulation in a dose-dependent manner even in the Ljharl and Gmnark mutant (Nakagawa and Kawaguchi 2006; Seo et al. 2007). This contradiction might be due to the specific distribution within the tissue that distinctively determines the outcome of JA signaling. In hypernodulating Gmnark mutants, an increase in JA might occur in restricted tissue, e.g., in vascular bundles (Hause et al. 2003; Nontachaiyapoom et al. 2007; Stenzel et al. 2003), whereas it is in contact with the entire leaf surface upon exogenous spraying. To understand how JA contributes to increasing nodulation in nark mutants, it is essential to determine the location of its activity through the use of JA-responsive reporter genes. Secondly, high concentrations of JA, mimicking wounding and pathogen attack and causing pleiotropic effects such as inhibition of shoot growth, lateral root formation, and loss in chlorophyll content (Nakagawa and Kawaguchi 2006), might further be responsible for the observed inhibition of colonization. The importance of JA concentration is illustrated by lateral root formation in rice, which is stimulated by exogenous applica- tion of JA up to a concentration of $2 \mu \mathrm{M}$ but is inhibited by higher concentrations (Wang et al. 2002). This is also evident from studies of the AM symbiosis in which JA application to shoots led to a diversity of results depending on JA concentration and frequency of application. Low concentrations of JA (5 $\mu \mathrm{M})$ applied once per week stimulated AM development in Allium sativum (Regvar et al. 1996). In contrast, spraying tomato leaves with 5 and $50 \mu \mathrm{M}$ MeJA twice a week reduced AM colonization in tomato (Herrera Medina et al. 2008) and so did treatment of leaves of Tropaeolum majus, Carica papaya, and Cucumis sativus with high concentrations of JA (0.05 to $5 \mathrm{mM}$ ) every second day (Ludwig-Müller et al. 2002). Also, the timing of JA application to mycorrhizal plants influenced colonization (Tejeda-Sartorius et al. 2008), possibly because JA responsiveness varies with the developmental stage of plants (Matthes et al. 2008). Tejeda-Sartorius and associates (2008) showed that a single treatment of two different tomato leaves with one drop of $5 \mu \mathrm{M}$ JA was sufficient to enhance AM colonization and arbuscule formation in the wild type and the JA-deficient mutant spr2. The extent to which colonization levels were raised depended on which day after AM inoculation JA was applied. When plants were treated with the same amount of JA for four times instead of only once, colonization was suppressed. These examples illustrate that conclusions drawn on the influence of systemic JA signaling on root symbioses might be biased if they are based on the application of a single JA concentration, a range of high concentrations, or on frequent application only, and it is necessary to carefully establish dose-response relationships. Furthermore, as stated before, pharmacological hormone and inhibitor application need to be combined with the use of plant mutants perturbed in JA biosynthesis and signaling in the same experimental setting to deepen our understanding of systemic JA signaling in root symbioses. A model summarizing the current knowledge on systemic JA action in mutualistic symbioses is given in Figure 1B.

\section{EXPLOITIVE ASSOCIATIONS WITH PLANT PARASITIC NEMATODES AND PARASITIC PLANTS}

Plant-parasitic nematodes and parasitic plants are obligate biotrophic pathogens of many plant species. In contrast to the symbiotic microorganisms discussed earlier, their infection process does not appear to be actively supported by the plant via plant-derived infection structures such as the PPA or the IT. Instead, they pierce the root in a cell-destructive manner and subsequently become biotrophic. Both parasites connect to the vascular cylinder to directly access plant nutrients. Nematodes induce dramatic developmental changes in plant roots by fundamentally manipulating root-cell behavior. In the root differentiation zone, root-knot nematodes (RKN) (members of the genus Meloidogyne) induce nuclear divisions without cell division leading to the formation of multinucleate giant cells that are connected to the vascular tissue and serve as feeding sites. The root cells that surround giant cells divide and swell, leading to the formation of root knots (Caillaud et al. 2008). Cyst nematodes (members of the genera Heterodera and Globodera) pierce and disrupt cortical cells while entering the root. Induction of feeding sites at the vascular cylinder leads to the breakdown of cell walls between neighboring cells, creating a multinucleate syncytium (Williamson and Gleason 2003). Parasitic plants of the genera Orobanche and Striga rely on carbohydrate nutrition from their dicotyledoneous or monocotyledoneous hosts, respectively, to complete their life cycle. After germination, parasitic plants form a haustorium that breaks into the host root, crosses the root cortex, and fuses 
with the vascular cylinder of the host plant to exploit nutrients (Rispail et al. 2007).

Compared with symbiotic interactions, less is known about JA and SA effects on particular steps of nematode or parasitic plant colonization. Therefore, we combine the description of those with effects on overall colonization. For both nematode and parasitic plant interactions, resistant and susceptible plant cultivars are known from a number of plant species. The use of such cultivars in comparative studies is useful to provide clues on the mechanisms involved in defense or compatibility and has yielded some information on the role of SA and JA signaling in these processes. The gene $M i-1$, encoding a nucleotide binding-LRR protein, confers resistance to RKN in tomato. In the tomato cultivar Motelle, which carries $M i-1$, RKN can still move to the central cylinder, but localized cell death occurs instead of giant-cell development (Ho et al. 1992). To test whether defense hormone pathways play a role in $M i-1-$ mediated resistance, Motelle hairy roots were transformed with the bacterial salicylatehydroxylase gene NahG to reduce SA content. In these roots, resistance to the RKN Meloidogyne javanica was strongly decreased and could be restored by application of the functional SA analogue benzothiadiazole (BTH). Therefore, resistance conferred by $M i-1$ is, at least in part, mediated via SA signaling (Branch et al. 2004). A second experiment suggested that relatively low levels of SA are sufficient to confer Mi-1-dependent resistance, because NahG plants degrading SA less efficiently than the hairy roots used by Branch and associates (2004) were not compromised in resistance (Bhattarai et al. 2008). In a further study, treatment of okra and cowpea with SA foliar spray caused a decrease in RKN infection (Nandi et al. 2003). SA application also reduced parasitism by cyst nematodes. Treatment of white clover and Arabidopsis with SA led to increased resistance without directly affecting nematode viability (Kempster et al. 2001; Wubben et al. 2008). Furthermore, a number of SA-deficient Arabidopsis mutants, namely sid2-1, deficient in isochorismate synthase required for SA synthesis (Wildermuth et al. 2001), pad4-1, affected in a lipase gene required for SA synthesis (Jirage et al. 1999), and NahG, were more susceptible to the cyst nematode Heterodera schachtii than was the wild type. The same was true for SA-insensitive mutants impaired in the SA-signaling component NPR1 (Cao et al. 1997). In turn, the nprl-supressor mutant snil (Li et al. 1999) displayed an elevated resistance to cyst nematodes (Wubben et al. 2008). Interestingly, in wild-type Arabidopsis, cyst-nematode infection caused an increase in SA levels in shoots but not in roots, which was paralleled by induction of $P R-1$ (encoding PATHOGENESIS-RELATED PROTEIN 1) a marker gene for SA signaling and systemic acquired resistance (SAR) (Wubben et al. 2008). The function of this SA elevation in shoots for cyst-nematode parasitism remains unclear. Nevertheless, it can be concluded that cyst-nematode infection induces SAR in Arabidopsis. The absence of SA induction in roots further illustrates that the role of a defense-signaling compound cannot necessarily be inferred directly from its levels in the tissue of interest.

Whereas SA signaling partly explains $\mathrm{Mi}$-1-mediated resistance, JA signaling is not involved (Bhattarai et al. 2008). Nevertheless, exogenous application of high concentrations of MeJA (up to $1.5 \mathrm{mM}$ ) to roots of oat and spinach and to shoots of tomato enhanced resistance to parasitic nematodes, possibly by elevating the level of compounds that are toxic to nematodes like phytoectosteroids, flavonoids, and proteinase inhibitors (Cooper et al. 2005; Soriano et al. 2004a and b). However, as discussed above, other pleiotropic effects like plant growth depression caused by application of high concentrations of
MeJA cannot be excluded. On the contrary, Bhattarai and associates (2008) found that, on roots of the tomato mutant jail, which is defective in the JA-Ile receptor component COI1, a lower number of RKN egg masses was produced as compared with wild-type roots. This indicates that COI1-mediated JA signaling promotes susceptibility to RKN. The endogenous JA level did not seem to be relevant, as the JA-deficient tomato mutant defl, defective in a yet-unknown component, had no quantitative phenotype (Bhattarai et al. 2008). On the other hand, the hypernodulating Lotus japonicus mutant harl was hyperinfected with RKN (Lohar and Bird 2003), which might be partly due to higher JA levels in the shoot, as shown for the mutant Gmnark, defective in the soybean orthologue of HAR1 (Kinkema and Gresshoff 2008). It is possible that, analogous to the interaction of Pseudomonas syringae with plant leaves, COI1-mediated RKN susceptibility is not actually caused by plant-produced JA-Ile but by an analogous molecule exuded by RKN to suppress SA signaling (Bhattarai et al. 2008).

Transcriptomics studies on whole soybean roots and lasercaptured syncytia suggest that JA signaling is suppressed during fully established compatible cyst-nematode interactions (Ithal et al. 2007a and b). Genes encoding JA-biosynthesis enzymes, such as $A O S$ and $A O C$, were downregulated in feeding structures induced by Heterodera glycines. However, OPDA Reductase 3 (OPR3), encoding the orthologue of Arabidopsis OPR3, which is critical for JA biosynthesis downstream of $A O S$ and $A O C$ (Stintzi and Browse 2000), was induced-a contradictory result that awaits further investigation. The biological role of the downregulation of JA genes encoding JAbiosynthesis enzymes is also unclear. It might be necessary to allow for the dramatic restructuring of root cells during syncytia formation or for the suppression of host defense responses.

Defense reactions during incompatible interactions between parasitic plants and resistant or partially resistant hosts range from i) HR-like necrosis and deposition of callose, lignin, and phenolic compounds in the cortex, at the endodermis or in vascular cylinder to ii) blockage of the vascular tissue by mucilage, probably to impair nutrient flux to the parasite (Lozano-Baena et al. 2007). Whereas application of JA to red clover had no effect on Orobanche infection (Kusumoto et al. 2007), several studies have shown that application of SA or its analogue, BTH, to roots or leaves of dicotyledoneous and monocotyledoneous host plants reduced parasitism by Orobanche and Striga spp., respectively (Hiraoka and Sugimoto 2008; Kusumoto et al. 2007; Müller-Stöver et al. 2005; Perez-de-Luque et al. 2004; Sauerborn et al. 2002). SA-induced defenses were visible at different steps of the interaction of Orobanche minor with Trifolium pratense (Kusumoto et al. 2007). Directed growth of parasite radicles towards SAtreated clover roots was blocked and radicle tips displayed bifurcate growth and papillate cells, suggesting that SA treatment leads to release of an inhibitory chemical by the host root. The second barrier occurred after cortical invasion by the parasite. The haustorium was stopped at the endodermis of the SA-treated host and was unable to fuse with the host vascular tissue, due to lignin-deposition in endodermal and fiber cells close to the intrusive cells of the parasite. Further evidence for the participation of SA signaling in defense against parasitic plants was provided by transcriptomics studies in which several SA-responsive genes were upregulated during attempted colonization in the rice cultivar Nipponbare, resistant to Striga hermonthica (Swarbrick et al. 2008), and the partially resistant sorghum cultivar Wad Ahmed (Hiraoka and Sugimoto 2008). In turn, JA-responsive genes were induced in compatible interactions of Orobanche spp. and their dicotyledoneous hosts (Die et al. 2007; Vieira Dos 
Santos et al. 2003a and b). The same occurred in the susceptible sorghum cultivars Abu70 and Tabat during colonization by Striga hermonthica while, simultaneously, SA-responsive genes were repressed. JA-responsive genes were only weakly upregulated in the more resistant sorghum cultivar Wad Ahmed (Hiraoka and Sugimoto 2008). It remains an open question whether JA signaling favors susceptibility to parasitic plants (e.g., by suppression of SA signaling) or if the increased JA response is a lateral effect induced in the host root due to cell-wall disruption and wounding caused by parasite penetration. Careful genetic analyses should help to shed light on this issue.

In summary, the emerging picture indicates that SA signaling generally promotes defense against root colonizing nematodes and parasitic plants similar to the general model derived from the well-studied leaf-biotroph interactions. Our current understanding of JA signaling in root-exploitive associations is less clear, because our knowledge is, so far, limited to circumstantial evidence derived from gene expression studies (Fig. 2).

\section{CONCLUSIONS}

This review summarizes the knowledge recently gained on the role of JA and SA signaling in root interactions with mutualistic and parasitic biotrophs. It has become evident that the signaling molecules SA and JA play a role in both mutualistic and parasitic interactions, showing that mechanisms used by the plant to find a balance between defense and accommodation may share some general features. The idea that SA signaling is preferentially involved in the activation of defense against biotrophic pathogens, which was obtained from studies on leaf pathogenesis, generally holds true for root-pathogen interactions and can be extended to mutualistic symbioses. For AM and rhizobial symbioses, SA-mediated defense responses seem to fine-tune the compatible interaction by providing a checkpoint at each colonization event like a passport control of the symbiotic microorganism. While evidence exists for a role of SA in incompatible interactions, it remains to be determined whether a similar preingress defense response is in place in compatible root interactions with parasitic plants and nematodes.

The role of JA signaling in root-biotroph interaction is less uniform. JA acts at multiple steps of colonization by AM fungi and rhizobia. In some cases, such as during presymbiotic calcium signaling, JA has an inhibitory effect, at least when applied exogenously. In other cases, such as arbuscule formation, it appears to promote accommodation. The colonization process of all four biotrophic colonizers discussed in this review involves dramatic cell-wall modification and degradation. A functional link between cell-wall stress and JA signaling is emerging, and it is tempting to speculate that JA has a role in supporting these cell-wall modifications. JA signaling systemically promotes or suppresses root colonization depending on plant species, concentration, and probably temporal and spatial distribution within the tissue. Divergent results have been obtained for AM and nematode colonization with mutants defective in coil and JA-biosynthesis. This suggests that COI1-independent JA signaling might exist in roots.

Our knowledge on SA and JA signaling in root interactions is still incomplete and fragmentary. In the recent past, it became evident that much can be learned from comparisons of different plant-microbe interactions. It is now time to rigorously dissect the role of SA and JA signaling in root interactions with a combination of genetics, pharmacological treatments, and live imaging. The availability of a set of biosynthetic and signaling mutants in the same plant species would be desirable to allow investigations of different root interactions in parallel.
A Nematode parasitism

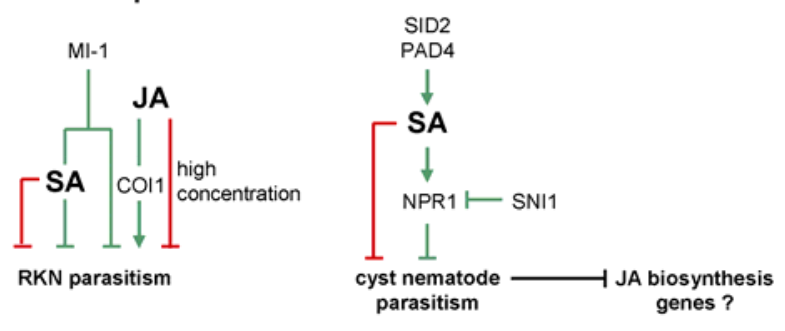

\section{B Parasitic plant parasitism}

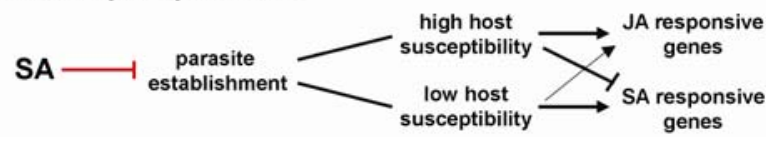

Fig. 2. A, Known impact of jasmonic acid (JA) and salicylic acid (SA) signaling on nematode parasitism. The repression of JA biosynthetic genes in cyst-nematode syncytia needs further investigation. B, Pharmacologically applied SA suppresses root colonization by parasitic plants. Highly susceptible host plants induce JA-responsive genes and suppress SA-responsive genes. Lowly susceptible to resistant host plants express SA-responsive genes and some express JA-responsive genes at low levels (thin black arrow). Green indicates evidence obtained via genetic approaches, and red displays evidence obtained by pharmacological application of the hormone. Black indicates that data were obtained in the wild type without pharmacological hormone application.

The model legumes Medicago truncatula and Lotus japonicus, which form symbiosis with AM fungi and rhizobia and are infected by nematodes and parasitic plants, are excellent candidates for such an approach.

\section{ACKNOWLEDGMENTS}

We apologize to all those researchers whose work we have overlooked or could not include due to space limitations. We thank I. F. Acosta and R. Sawers for helpful discussions and comments on the manuscript. C. Gutjahr is supported by Ph.D. scholarships of the Studienstiftung des Deutschen Volkes (German National Academic Foundation) and the Roche Research Foundation (Switzerland) and U. Paszowski by the Swiss National Science Foundation "professeur boursier" grant PP00A-110874.

\section{LITERATURE CITED}

Allen, G., Chu, S., Harrington, C., Schumacher, K., Hoffmann, T., Tang, Y., Grill, E., and Schröder, J. 2001. A defined range of guard cell calcium oscillation parameters encodes stomatal movements. Nature 411:1053-1057.

Armengaud, P., Breitling, R., and Amtmann, A. 2004. The potassium-dependent transcriptome of Arabidopsis reveals a prominent role of jasmonic acid in nutrient signaling. Plant Physiol. 136:2556-2576.

Babst, B., Ferrieri, R., Gray, D., Lerdau, M., Schlyer, D., Schueller, M., Thorpe, M., and Orians, C. 2005. Jasmonic acid induces rapid changes in carbon transport and partitioning in Populus. New Phytol. 167:63-72.

Balbi, V., and Devoto, A. 2008. Jasmonate signaling network in Arabidopsis thaliana: Crucial regulatory nodes and new physiological scenarios. New Phytol. 177:301-318.

Balestrini, R., and Bonfante, P. 2005. The interface compartment in arbuscular mycorrhizae: A special type of plant cell wall? Plant Biosyst. 139:8-15.

Bari, R., and Jones, J. 2009. Role of plant hormones in plant defence responses. Plant Mol. Biol. 69:473-488.

Baron, C., and Zambryski, P. 1995. The plant response in pathogenesis, symbiosis and wounding: Variations on a common theme? Annu. Rev. Genet. 29:107-129.

Beckers, G., and Spoel, S. 2006. Fine-tuning plant defence signaling: Salicylate versus jasmonate. Plant Biol. 8:1-10.

Bhattarai, K. K., Xie, Q.-G., Mantelin, S., Bishnoi, U., Girke, T., Navarre, D. A., and Kaloshian, I. 2008. Tomato susceptibility to root-knot nematodes requires an intact jasmonic acid signaling pathway. Mol. PlantMicrobe Interact. 21:1205-1214. 
Blilou, I., Ocampo, J., and García Garrido, J. 1999. Resistance of pea roots to endomycorrhizal fungus or Rhizobium correlates with enhanced levels of endogeneous salicylic acid. J. Exp. Bot. 50:1663-1668.

Blilou, I., Ocampo, J., and Garcia-Garrido, J. 2000. Induction of Ltp (lipid transfer protein) and PAL (phenylalanine ammonia lyase) gene expression in rice roots colonized by the arbuscular mycorrhizal fungus Glomus mossae. J. Exp. Bot. 51:1969-1977.

Branch, C., Hwang, C.-F., Navarre, D. A., and Williamson, V. M. 2004 Salicylic acid is part of the Mi-1-mediated defense response to rootknot nematode in tomato. Mol. Plant-Microbe Interact. 17:351-356.

Brooks, D., Bender, C., and Kunkel, B. 2005. The Pseudomonas syringae phytotoxin coronatine promotes virulence by overcoming salicylic acid dependent defences in Arabidopsis thaliana. Mol. Plant Pathol. 6:629639

Browse, J. 2009. Jasmonate passes muster: A receptor and targets for the defense hormone. Ann. Rev. Plant Biol. 60.

Caillaud, M.-C., Dubreuil, G., Quentin, M., Perfus-Barbeoch, L., Lecomte, P., de Almeida Engler, J., Abad, P., Rosso, M.-N., and Favery, B. 2008. Root-knot nematodes manipulate plant cell functions during a compatible interaction. J. Plant Physiol. 165:104-113.

Cao, H., Glazebrook, J., Clarke, J. D., Volko S., and Dong, X. 1997. The Arabidopsis NPR1 gene that controls systemic acquired resistance encodes a novel protein containing ankyrin repeats. Cell 88:57-63.

Catford, J.-G., Staehelin, C., Lerat, S., Piche Y., and Vierheilig, H. 2003. Suppression of arbuscular mycorrhizal colonization and nodulation in split-root systems of alfalfa after pre-inoculation and treatment with Nod factors. J. Exp. Bot. 54:1481-1487.

Cooper, W., Jia, L., and Goggin, L. 2005. Effects of jasmonate-induced defences on root-knot nematode infection of resistant and susceptible tomato cultivars. J. Chem. Ecol. 31:1953-1967.

Creelman, R., and Mullet, J. 1995. Jasmonic acid distribution and action in plants: Regulation during development and response to biotic and abiotic stress. Proc. Natl. Acad. Sci. U.S.A. 92:4114-4119.

Dathe, N., Parry, A., Heald, J., Scott, I., Miersch, O., and Horgan, R. 1994. Jasmonic acid and abscisic acid in shoots, coleoptiles, and roots of wheat seedlings. J. Plant Growth Regul. 13:59-62.

Die, J. V., Dita, M. A., Krajinski, F., González-Verdejo, C. I., Rubiales, D., Moreno, M. T., and Román, B. 2007. Identification by suppression subtractive hybridization and expression analysis of Medicago truncatula putative defence genes in response to Orobanche crenata parasitization. Physiol. Mol. Plant Pathol. 70:49-59.

Ding, Y., and Oldroyd, G. 2009. Positioning the nodule: The hormone dictum. Plant Sig. Behav. 4:85-89.

Dombrecht, B., Xue, G. P., Sprague, S. J., Kirkegaard, J. A., Ross, J. J., Reid, J. B., Fitt, G. P., Sewelam, N., Schenk, P. M., Manners, J. M., and Kazan, K. 2007. MYC2 differentially modulates diverse jasmonate-dependent functions in Arabidopsis. Plant Cell 19:2225-2245.

Duc, G., Trouvelot, A., Gianinazzi-Pearson, V., and Gianinazzi, S. 1989. First report of nonmycorrhizal plant mutants $\left(\mathrm{Myc}^{-}\right)$obtained in pea (Pisum sativum L.) and faba bean (Vicia faba L.). Plant Sci. 60:215222

Ellis, C., Karafyllidis, I., Wasternack, C., and Turner, J. 2002. The Arabidopsis mutant cev1 links cells wall signaling to jasmonate and ethylene responses. Plant Cell 14:1557-1566.

Farmer, E. E. 2007. Jasmonate perception machines. Nature 448:659-660.

Fournier, J., Timmers, A. C. J., Sieberer, B. J., Jauneau, A., Chabaud, M., and Barker, D. G. 2008. Mechanism of infection thread elongation in root hairs of Medicago truncatula and dynamic interplay with associated rhizobial colonization. Plant Physiol. 148:1985-1995.

Fuller, V., Lilley, C., and Urwin, P. 2008. Nematode resistance. New Phytol. 180:27-44.

Gaffney, T., Friedrich, L., Vernooij, B., Negrotto, D., Nye, G., Uknes, S., Ward, E., Kessmann, H., and Ryals, J. 1993. Requirement of salicylic acid for the induction of systemic acquired resistance. Science 261:754756

Garcia-Brugger, A., Lamotte, O., Vandelle, E., Bourque, S., Lecourieux, D., Poinssot, B., Wendehenne, D., and Pugin, A. 2006. Early signaling events induced by elicitors of plant defenses. Mol. Plant-Microbe Interact. 19:711-724

Garcia-Garrido, J., and Ocampo, J. 2002. Regulation of the plant defence response in arbuscular mycorrhizal symbiosis. J. Exp. Bot. 53:13771386.

Genre, A., and Bonfante, P. 1998. Actin versus tubulin configuration in arbuscule-containing cells from mycorrhizal tobacco roots. New Phytol. 140:745-752.

Genre, A., and Bonfante, P. 2002. Epidermal cells of a symbiosis-defective mutant of Lotus japonicus show altered cytoskeleton organization in the presence of a mycorrhizal fungus. Protoplasma 219:43-50.

Genre, A., Chabaud, M., Timmers, T., Bonfante, P., and Barker, D. G. 2005. Arbuscular mycorrhizal fungi elicit a novel intracellular apparatus in Medicago truncatula root epidermal cells before infection. Plant Cell 17:3489-3499.

Gianinazzi-Pearson, V., Dumas-Gaudot, E., Gollotte, A., Tahiri-Alaoui, A. and Gianinazzi, S. 1996. Cellular and molecular defence-related root responses to invasion by arbuscular mycorrhizal fungi. New Phytol. 133:45-57.

Glazebrook, J. 2005. Contrasting mechanisms of defence against biotrophic and necrotrophic pathogens. Annu. Rev. Phytopathol. 43:205-227.

Glazebrook, J., Chen, W., Estes, B., Chang, H.-S., Nawrath, C., Metraux, J.-P., Zhu, T., and Katagiri, F. 2003. Topology of the network integrating salicylate and jasmonate signal transduction derived from global expression phenotyping. Plant J. 34:217-228.

Godiard, L., Niebel, A., Micheli, F., Gouzy, J., Ott, T., and Gamas, P. 2007. Identification of new potential regulators of the Medicago truncatula-Sinorhizobium meliloti symbiosis using a large-scale suppression subtractive hybridization approach. Mol. Plant-Microbe Interact. 20:321-332.

Gollotte, A., Gianinazzi-Pearson, V., Giovenetti, M., Sbrana, C., Avio, L., and Gianinazzi, S. 1993. Cellular localization and cytochemical probing of resistance reactions to arbuscular mycorrhizal fungi in a 'locus a' mutant of Pisum sativum L. Planta 191:112-122.

Hause, B., and Fester, T. 2005. Molecular and cell biology of arbuscular mycorrhizal symbiosis. Planta 221:184-196.

Hause, B., Meier, W., Miersch, O., Kramell, R and Strack, D. 2002. Induction of jasmonate biosynthesis in arbuscular mycorrhizal barley roots. Plant Physiol. 130:1213-1220.

Hause, B., Hause, G., Kutter, C., Miersch, O., and Wasternack, C. 2003. Enzymes of jasmonate biosynthesis occur in tomato sieve elements. Plant Cell Physiol. 44:643-648.

Hause, B., Mrosk, C., Isayenkov, S., and Strack, D. 2007. Jasmonate in arbuscular mycorrhizal interactions. Phytochemistry 68:101-110.

Henkes, G., Thorpe, M., Minchin, P., Schurr, U., and Röse, U. 2008. Jasmonic acid treatment to part of the root system is consistent with simulated leaf herbivory, diverting recently assimilated carbon towards untreated roots within an hour. Plant Cell Environ. 31:1229-1236.

Herrera Medina, M. J., Gagnon, H., Piché, Y., Ocampo, J. A., García, Garrido, J. M., and Vierheilig, H. 2003. Root colonization by arbuscular mycorrhizal fungi is affected by the salicylic acid content of the plant. Plant Sci. 164:993-998.

Herrera Medina, M. J., Tamayo, M., Vierheilig, H., Ocampo, J., and García Garrido, J. 2008. The jasmonic acid signaling pathway restricts the development of the arbuscular mycorrhizal association in tomato. J. Plant Growth Regul. 27:221-230.

Hiraoka, Y., and Sugimoto, Y. 2008. Molecular responses of sorghum to purple witchweed (Striga hermonthica) parasitism. Weed Sci. 56:356363.

Hirsch, A., Lum, M., and Downie, J. 2001. What makes the rhizobia-legume symbiosis so special? Plant Physiol. 127:1484-1492.

Ho, J., Weide, R., Ma, H., Wordragen, M., Lambert, K., Koornneef, M., Zabel, P., and Williamson, V. M. 1992. The root-knot nematode resistance gene $(\mathrm{Mi})$ in tomato: Construction of a molecular linkage map and identification of dominant cDNA markers in resistant genotypes. Plant J. 2:971-982.

Isayenkov, S., Mrosk, C., Stenzel, I., Strack, D., and Hause, B. 2005. Suppression of allene oxide cyclase in hairy roots of Medicago truncatula reduces jasmonate levels and the degree of mycorrhization with Glomus intraradices. Plant Physiol. 139:1401-1410.

Ithal, N., Recknor, J., Nettleton, D., Hearne, L., Maier, T., Baum, T. J., and Mitchum, M. G. 2007a. Parallel genome-wide expression profiling of host and pathogen during soybean cyst nematode infection of soybean. Mol. Plant-Microbe Interact. 20:293-305.

Ithal, N., Recknor, J., Nettleton, D., Maier, T., Baum, T. J., and Mitchum, M. G. 2007b. Developmental transcript profiling of cyst nematode feeding cells in soybean roots. Mol. Plant-Microbe Interact. 20:510-525.

Jirage, D., Tootle, T. L., Reuber, T. L., Frost, L. N., Feys, B. J., Parker, J. E., Ausubel, F. M., and Glazebrook, J. 1999. Arabidopsis thaliana PAD4 encodes a lipase-like gene that is important for salicylic acid signaling. Proc. Natl. Acad. Sci. U.S.A. 96:13583-13588.

Katsir, L., Schilmiller, A. L., Staswick, P. E., He, S. Y., and Howe, G. A. 2008. COI1 is a critical component of a receptor for jasmonate and the bacterial virulence factor coronatine. Proc. Natl. Acad. Sci. U.S.A. 105:1700-1705.

Kempster, V., Davies, K., and Scott, E. 2001. Chemical and biological induction of resistance to the clover cyst nematode (Heterodera trifolii) in white clover (Trifolium repens). Nematology 3:35-43.

Kinkema, M., and Gresshoff, P. M. 2008. Investigation of downstream signals of the soybean autoregulation of nodulation receptor kinase GmNARK. Mol. Plant-Microbe Interact. 21:1337-1348.

Ko, J.-H., Kim, J. H., Jayanty, S. S., Howe, G. A., and Han, K.-H. 2006. Loss of function of COBRA, a determinant of oriented cell expansion, 
invokes cellular defence responses in Arabidopsis thaliana. J. Exp. Bot. 57:2923-2936.

Koda, Y. 1997. Possible involvement of jasmonate in various morphogenic events. Physiol. Plant. 100:639-646.

Koornneef, A., Leon-Reyes, A., Ritsema, T., Verhage, A., Den Otter, F. C., Van Loon, L. C., and Pieterse, C. M. J. 2008. Kinetics of salicylate-mediated suppression of jasmonate signaling reveal a role for redox modulation. Plant Physiol. 147:1358-1368.

Kosuta, S., Chabaud, M., Lougnon, G., Gough, C., Dénarié, J., Barker, D., and Becard, G. 2003. A diffusible factor from arbuscular mycorrhizal fungi induces symbiosis-specific $M t$ ENOD11 expression in roots of Medicago truncatula. Plant Physiol. 131:952-962.

Kosuta, S., Hazledine, S., Sun, J., Miwa, H., Morris, R. J., Downie, J. A., and Oldroyd, G. E. D. 2008. Differential and chaotic calcium signatures in the symbiosis signaling pathway of legumes. Proc. Natl. Acad. Sci. U.S.A. 105:9823-9828,

Kouchi, H., Shimomura, K., Hata, S., Hirota, A., Wu, G.-J., Kumagai, H., Tajima, S., Suganuma, N., Suzuki, A., Aoki, T., Hayashi, M., Yokoyama, T., Ohyama, T., Asamizu, E., Kuwata, C., Shibata, D., and Tabata, S. 2004. Large-scale analysis of gene expression profiles during early stages of root nodule formation in a model legume, Lotus japonicus. DNA Res. 11:263-274.

Krusell, L., Madsen, L., Sato, S., Aubert, G., Genua, A., Szczyglowski, K., Duc, G., Kaneko, T., Tabata, S., De Bruijn, F., Pajuelo, E., Sandal, N., and Stougaard, J. 2002. Shoot control of root development and nodulation is mediated by a receptor-like kinase. Nature 420:422-426.

Kucey, R., and Paul, E. 1982. Carbon flow photosynthesis and N2-fixation in mycorrhizal and nodulated faba beans (Vicia faba L.) Soil Biol. Biochem. 14 407-412.

Kusumoto, D., Goldwasser, Y., Xie, X., Yoneyama, K., Takeuchi, Y., and Yoneyama, K. 2007. Resistance of red clover (Trifolium pratense) to the root parasitic plant Orobanche minor is activated by salicylate but not by jasmonate. Ann. Bot. 100:537-544.

Laurie-Berry, N., Joardar, V., Street, I., and Kunkel, B. 2006. The Arabidopsis thaliana JASMONATE INSENSITIVE1 gene is required for suppression of salicylic acid-dependent defenses during infection by Pseudomonas syringae. Mol. Plant-Microbe Interact. 19:789-800.

Li, C., Liu, G., Xu, C., Lee, G. I., Bauer, P., Ling, H.-Q., Ganal, M. W., and Howe, G. A. 2003. The tomato suppressor of prosystemin-mediated responses 2 gene encodes a fatty acid desaturase required for the biosynthesis of jasmonic acid and the production of a systemic wound signal for defense gene expression. Plant Cell 15:1646-1661.

Li, L., Li, C., and Howe, G. A. 2001. Genetic analysis of wound signaling in tomato. Evidence for a dual role of jasmonic acid in defense and female fertility. Plant Physiol. 127:1414-1417.

Li, X., Zhang, J., Clarke, J. D., Li, J., and Dong, X. 1999. Identification and cloning of a negative regulator of systemic acquired resistance, SNI1, through a screen for suppressors of npi1-1. Cell 98:329-339.

Lipka, U., Fuchs, R., and Lipka, V. 2008. Arabidopsis non-host resistance to powdery mildews. Curr. Opin. Plant Biol. 11:404-411.

Liu, J., Blaylock, L., Endre, G., Cho, J., Town, C., VandenBosch, K., and Harrison, M. 2003. Transcript profiling coupled with spatial expression analysis reveals genes involved in distinct developmental stages of the arbuscular mycorrhizal symbiosis. Plant Cell 15:2106-2123.

Loake, G., and Grant, M. 2007. Salicylic acid in plant defence-the players and protagonists. Curr. Opin. Plant Biol. 10:466-472.

Lohar, D. P., and Bird, D. M. 2003. Lotus japonicus: A new model to study root-parasitic nematodes. Plant Cell Physiol. 44:1176-1184.

López, M. A., Bannenberg, G., and Castresana, C. 2008. Controlling hormone signaling is a plant and pathogen challenge for growth and survival. Curr. Opin. Plant Biol. 11:420-427.

Lorenzo, O., and Solano, R. 2005. Molecular players regulating the jasmonate signaling network. Curr. Opin. Plant Biol. 8:532-540.

Lorenzo, O., Chico, J. M., Sanchez-Serrano, J. J., and Solano, R. 2004. JASMONATE-INSENSITIVE1 encodes a MYC transcription factor essential to discriminate between different jasmonate-regulated defense responses in Arabidopsis. Plant Cell 16:1938-1950.

Lozano-Baena, M. D., Prats, E., Moreno, M. T., Rubiales, D., and Perezde-Luque, A. 2007. Medicago truncatula as a model for nonhost resistance in legume-parasitic plant interactions. Plant Physiol. 145:437-449.

Ludwig-Müller, J., Bennett, R., García-Garrido, J., Piché, Y., and Vierheilig, H. 2002. Reduced arbuscular mycorrhizal root colonization in Tropaeolum majus and Carica papaya after jasmonic acid application cannot be attributed to increased glucosinolate. J Plant Physiol. 159:517-523.

Mabood, F., Souleimanov, A., Khan, W., and Smith, D. L. 2006. Jasmonates induce Nod factor production by Bradyrhizobium japonicum. Plant Physiol. Biochem. 44:759-765.

Martinez-Abarca, F., Herrera-Cervera, J. A., Bueno, P., Sanjuan, J., Bisseling, T., and Olivares, J. 1998. Involvement of salicylic acid in the establishment of the Rhizobium meliloti-alfalfa symbiosis. Mol. Plant-
Microbe Interact. 11:153-155.

Mathesius, U. 2003. Conservation and divergence of signaling pathways between roots and soil microbes-The Rhizobium-legume symbiosis compared to the development of lateral roots, mycorrhizal interactions and nematode-induced galls. Plant Soil 225:105-119.

Matsuki, T., Tazaki, H., Fujimori, T., and Hogetsu, T. 1992. The influence of jasmonic acid methyl ester on microtubules in potato cells and formation of potato tubers. Biosci. Biotechnol. Biochem. 56:1329-1330.

Matthes, M., Pickett, J., and Napier, J. 2008. Natural variation in responsiveness of Arabidopsis thaliana to methyl jasmonate is developmentally regulated. Planta 228:1021-1028.

Meixner, C., Ludwig-Müller, J., Miersch, O., Gresshoff, P., Staehelin, C., and Vierheilig, H. 2005. Lack of mycorrhizal autoregulation and phytohormonal changes in the supernodulating soybean mutant nts1007. Planta 222:709-715.

Mitra, R. M., and Long, S. R. 2004. Plant and bacterial symbiotic mutants define three transcriptionally distinct stages in the development of the Medicago truncatula/Sinorhizobium meliloti symbiosis. Plant Physiol. 134:595-604.

Miwa, H., Sun, J., Oldroyd, G., and Downie, J. A. 2007. Analysis of calcium spiking using a cameleon calcium sensor reveals that nodulation gene expression is regulated by calcium spike number and the developmental status of the cell. Plant J. 48:883-894.

Müller-Stöver, D., Buschmann, H., and Sauerborn, J. 2005. Increasing control reliability of Orobanche cumana through integration of a biocontrol agent with a resistance-inducing chemical. Eur. J. Plant Pathol. 111:193-202.

Mur, L. A. J., Kenton, P., Atzorn, R., Miersch, O., and Wasternack, C. 2006. The outcomes of concentration-specific interactions between salicylate and jasmonate signaling include synergy, antagonism, and oxidative stress leading to cell death. Plant Physiol. 140:249-262.

Nakagawa, T., and Kawaguchi, M. 2006. Shoot-applied MeJA suppresses root nodulation in Lotus japonicus. Plant Cell Physiol. 47:176-180.

Nandi, B., Kundu, K., Banerjee, N., and Sinha Babu, S. 2003. Salicylic acid induced suppression of Meloidogyne incognita infestation of okra and cowpea. Nematology 5:747-752.

Niehaus, K., Kapp, D., and Pühler, A. 1993. Plant defence and delayed infection of alfalfa pseudonodules induced by an exopolysaccharide (EPS-I)-deficient Rhizobium meliloti mutant. Planta 190:415-425.

Nishimura, R., Hayashi, M., Wu, G., Kouchi, H., Imaizumi-Anraku, H., Murakami, Y., Kawasaki, S., Akao, S., Ohmori, M., Nagasawa, M., Harada, K., and Kawaguchi, M. 2002. HAR1 mediates systemic regulation of symbiotic organ development. Nature 420:426-429.

Nontachaiyapoom, S., Scott, P., Men, A., Kinkema, M., Schenk, P., and Gresshoff, P. 2007. Promoters of orthologues Glycine max and Lotus japonicus autoregulation genes interchangeably drive phloem-specific expression in transgenic plants. Mol. Plant-Microbe Interact. 20:769780.

Olah, B., Brière, C., Bécard, G., Dénarié, J., and Gough, C. 2005. Nod factors and a diffusible factor from arbuscular mycorrhizal fungi stimulate lateral root formation in Medicago truncatula via the DMI1/DMI2 signaling pathway. Plant J. 44:195-207.

Oldroyd, G., and Downie, J. A. 2008. Coordinating nodule morphogenesis with rhizobial infection in legumes. Annu. Rev. Plant Biol. 59:519-546.

Parniske, M. 2000. Intracellular accommodation of microbes by plants: A common developmental program for symbiosis and disease? Curr. Opin. Plant Biol. 3:320-328.

Parniske, M. 2008. Arbuscular mycorrhiza: The mother of plant root endosymbioses. Nat. Rev. Microbiol. 6:763-775.

Paszkowski, U. 2006. Mutualism and parasitism: The yin and yang of plant symbioses. Curr. Opin. Plant Biol. 9:364-370.

Perez-de-Luque, A., Jorrín, J., and Rubiales, D. 2004. Crenate broomrape control in pea by foliar application of benzothiadiazole (BTH). Phytoparasitica 32:21-29.

Perotto, S., Brewin, N., and Kannenberg, E. 1994. Cytological evidence for a host defence response that reduces cell and tissue invasion in pea nodules by lipopolysaccharide-defective mutants of Rhizobium leguminosarum strain 3841. Mol. Plant-Microbe Interact. 7:99-112.

Radutoiu, S., Madsen, L. H., Madsen, E., Jurkiewicz, A., Fukai, E., Quistgaard, E. M. H., Albrektsen, A., James, E. K., Thirup, S., and Stougaard, J. 2007. LysM domains mediate lipochitin-oligosaccharide recognition and $N f r$ genes extend the symbiotic host range. EMBO (Eur. Mol. Biol. Organ.) J. 26:3923-3935.

Regvar, M., Gogala, N., and Zalar, P. 1996. The effect of jasmonic acid on mycorrhizal Allium sativum. New Phytol. 134:703-707.

Riedel, T., Groten, K., and Baldwin, I. T. 2008. Symbiosis between Nicotiana attenuata and Glomus intraradices: Ethylene plays a role, jasmonic acid does not. Plant Cell Environ. 31:1203-1213.

Rispail, N., Dita, M., Gonzalez-Verdejo, C., Pèrez-de-Luque, A., Castillejo, M., Prats, E., Román, B., Jorín, J., and Rubiales, D. 2007. Plant resis- 
tance to parasitic plants: Molecular approaches to an old foe. New Phytol. 173:703-712.

Robert-Seilaniantz, A., Navarro, L., Bari, R., and Jones, J. D. G. 2007. Pathological hormone imbalances. Curr. Opin. Plant Biol. 10:372-379.

Rosas, S., Soria, R., Correa, N., and Abdala, G. 1998. Jasmonic acid stimulates the expression of nod-genes in rhizobium. Plant Mol. Biol. 38:1161-1168.

Sauerborn, J., Buschmann, H., Ghiasvand Ghiasi, K., and Kogel, K.-H 2002. Benzothiadiazole activates resistance to sunflower (Helianthus anuus) in the root-parasitic weed Orobanche cumana. Phytopathology 92:59-64.

Schmelz, E. A., Alborn, H. T., Engelberth, J., and Tumlinson, J. H. 2003. Nitrogen deficiency increases volicitin-induced volatile emission, jasmonic acid accumulation, and ethylene sensitivity in maize. Plant Physiol. 133:295-306.

Schnabel, E., Journet, E., de Carvalho-Niebel, F., Duc, G., and Frugoli, J. 2005. The Medicago truncatula SUNN gene encodes a CLV1-like leucine-rich repeat receptor kinase that regulates nodule number and root length. Plant. Mol. Biol. 58:809-822.

Searle, I., Men, A., Laniya, T., Buzas, D., Iturbe-Ormaetxe, I., Caroll, B., and Gresshoff, P. 2003. Long-distance signaling in nodulation directed by a CLAVATA1-like receptor kinase. Science 299:109-112.

Seo, H., Li, J., Lee, S., Yu, J., Kim, K., Lee, S., Lee, I., and Paek, N. 2007. The hypernodulating $n t s$ mutation induces jasmonate synthetic pathway in soybean leaves. Mol. Cells 24:185-193.

Shrihari, P., Sakamoto, K., Inubushi, K., and Akao, S. 2000. Interaction between supernodulating or non-nodulating mutants of soybean and two arbuscular mycorrhizal fungi. Mycorrhiza 10:101-106.

Siciliano, V., Genre, A., Balestrini, R., Cappellazzo, G., deWit, P. J. G. M., and Bonfante, P. 2007. Transcriptome analysis of arbuscular mycorrhizal roots during development of the prepenetration apparatus. Plant Physiol. 144:1455-1466.

Solaiman, M., Senoo, K., Kawaguchi, M., Imaizumi-Anraku, H., Akao, S., Tanaka, A., and Obata, H. 2000. Characterization of mycorrhizas formed by Glomus sp. on roots of hypernodulating mutants of Lotus japonicus. J. Plant Res. 113:443-448.

Soriano, I., Asenstorfer, R., Schmidt, O., and Riley, I. 2004a. Inducible flavone in oats (Avena sativa) is a novel defence against plant parasitic nematodes. Phytopathology 94:1207-1214.

Soriano, I., Riley, I., Potter, M., and Bowers, W. 2004b. Phytoectysteroids: A novel defence against plant parasitc nematodes. J. Chem. Ecol. 30:1885-1899.

Spoel, S. H., and Dong, X. 2008. Making sense of hormone crosstalk during plant immune responses. Cell Host Microbe 3:348-351.

Stacey, G., McAlvin, C. B., Kim, S.-Y., Olivares, J., and Soto, M. J. 2006. Effects of endogenous salicylic acid on nodulation in the model legumes Lotus japonicus and Medicago truncatula. Plant Physiol. 141:1473-1481.

Stenzel, I., Hause, B., Maucher, H., Pitzschke, A., Miersch, O., Ziegler, J., Ryan, C., and Wasternack, C. 2003. Allene oxide cyclase dependence of the wound response and vascular bundle-specific generation of jasmonates in tomato; amplification in wound signaling. Plant J. 33:577-589.

Stenzel, I., Hause, B., Proels, R., Miersch, O., Oka, M., Roitsch, T., and Wasternack, C. 2008. The AOC promoter of tomato is regulated by developmental and environmental stimuli. Phytochemistry 69:1859-1869.

Stintzi, A., and Browse, J. 2000. The Arabidopsis male-sterile mutant, opr3, lacks the 12-oxophytodienoic acid reductase required for jasmonate synthesis. Proc. Natl. Acad. Sci. U.S.A. 97:10625-10630.

Stumpe, M., Carsjens, J., Stenzel, I., Göbel, C., Lang, I., Pawlowski, K., Hause, B., and Feussner, I. 2005. Lipid metabolism in arbuscular mycorrhizal roots of Medicago truncatula. Phytochemistry 66:781-791.
Sun, J., Cardoza, V., Mitchell, D., Bright, L., Oldroys, G., and Harris, J. 2006. Crosstalk between jasmonic acid, ethylene and Nod factor signaling allows integration of diverse inputs for regulation of nodulation. Plant J. 46:961-970.

Swarbrick, P. J., Huang, K., Liu, G., Slate, J., Press, M. C., and Scholes, J. D. 2008. Global patterns of gene expression in rice cultivars undergoing a susceptible or resistant interaction with the parasitic plant Striga hermonthica. New Phytol. 179:515-529.

Swiatek, A., Lenjou, M., Van Bockstaele, D., Inze, D., and Van Onckelen, H. 2002. Differential effect of jasmonic acid and abscisic acid on cell cycle progression in Tobacco BY-2 Cells. Plant Physiol. 128:201-211.

Takahashi, K., Fujino, K., Kikuta, Y., and Koda, Y. 1994. Expansion of potato cells in response to jasmonic acid. Plant Sci. 100:3-8.

Tang, Z., Sadka, A., Morishige, D. T., and Mullet, J. E. 2001. Homeodomain leucine zipper proteins dind to the phosphate response domain of the soybean VspB tripartite promoter. Plant Physiol. 125:797-809.

Tejeda-Sartorius, M., Martinez de la Vega, O., and Délano-Frier, J. 2008. Jasmonic acid influences mycorrhizal colonization in tomato plants by modifying the expression of genes involved in carbohydrate partitioning. Physiol. Plant. 133:339-353.

van Spronsen, P. C., Tak, T., Rood, A. M. M., van Brussel, A. A. N., Kijne, J. W., and Boot, K. J. M. 2003. Salicylic acid inhibits indeterminatetype nodulation but not determinate-type nodulation. Mol. PlantMicrobe Interact. 16:83-91.

Vasse, D., de Billy, F., and Truchet, G. 1993. Abortion of infection during the Rhizobium meliloti-alfalfa symbiotic interaction is accompanied by a hypersensitive reaction. Plant J. 4:555-566.

Vieira Dos Santos, C., Delavault, P., Letousey, P., and Thalouarn, P. 2003a. Identification by suppression subtractive hybridization and expression analysis of Arabidopsis thaliana putative defence genes during Orobanche ramosa infection. Physiol. Mol. Plant Pathol. 62:297-303.

Vieira Dos Santos, C., Letouseyy, P., Delavault, P., and Thalouarn, P. 2003b. Defence gene expression analysis of Arabidopsis thaliana parasitized by Orobanche ramosa. Phytopathology 93:451-457.

Wang, G., Coleman, D., Freckman, D., Dyer, M., McNaughton, S., Acra, M., and Goeschl, J. 1989. Carbon partitioning patterns of mycorrhizal versus non-mycorrhizal plants: Real-time dynamic measurements using ${ }^{11} \mathrm{CO}_{2}$. New Phytol. 112:489-493.

Wang, S., Ichii, M., Taketa, S., Xu, L., Xia, K. a. i., and Zhou, X. i. e. 2002. Lateral root formation in rice (Oryza sativa): Promotion effect of jasmonic acid. J. Plant Physiol. 159:827-832.

Wasson, A. P., Pellerone, F. I., and Mathesius, U. 2006. Silencing the flavonoid pathway in Medicago truncatula inhibits root nodule formation and prevents auxin transport regulation by rhizobia. Plant Cell 18:16171629.

Wildermuth, M. C., Dewdney, J., Wu, G., and Ausubel, F. M. 2001. Isochorismate synthase is required to synthesize salicylic acid for plant defence. Nature 414:562-565.

Williamson, V. M., and Gleason C. A. 2003. Plant-nematode interactions. Curr. Opin. Plant Biol. 6:327-333.

Wright, D., Read, D., and Schooles, J. 1998. Mycorrhizal sink strength influences whole plant carbon balance of Trifolium repens L. Plant Cell Environ. 21:881-891.

Wubben, M. J. E., Jin, J., and Baum, T. J. 2008. Cyst nematode parasitism of Arabidopsis thaliana is inhibited by salicylic acid (SA) and elicits uncoupled SA-independent pathogenesis-related gene expression in roots. Mol. Plant-Microbe Interact. 21:424-432.

Xie, Z., Müller, J., Wiemken, A., Broughton, W., and Boller, T. 1998. Nod factors and tri-iodobenzoic acid stimulate mycorrhizal colonization and affect carbohydrate partitioning in Lablab purpureus. New Phytol. 139:361-366. 